\title{
Primipar Kadınların Doğum Deneyim Algıları Üzerine Doğum Beklentilerinin Etkisi*
}

\author{
The Influence of Childbirth Expectation on Primiparous Women's \\ Perceptions of their Birth Experience
}

\section{Şemsi ASLAN, ${ }^{a}$ Filiz OKUMUŞ ${ }^{b}$}

ÖZET Amaç: Bu araştırma, özel hastanede vajinal doğum yapan veya sezaryen olan primipar kadınların doğum deneyim algıları üzerine doğum beklentilerinin etkisini belirlemek amacıyla yapılmıştır. Gereç ve Yöntem: Araştırma, retrospektif ve tanımlayıcı niteliktedir. Araştırma, Medipol Sağlık Grubu'na bağlı özel bir hastanede yapılmıştır. Araştırmanın örneklemi 2014 yılı Şubat-Temmuz aylarında araştırmanın yapıldığ 1 hastaneye başvuran ve araştırmaya katılmayı kabul eden 450 primipar kadın oluşturmuştur. Verilerin toplanmasında araştırmacılar tarafından yarı yapılandırılmış "Beklenti Değerlendirme Soru Formu” kullanılmıştır. Verilerin değerlendirilmesinde Ki-Kare testi, Fisher’s Exact Ki-Kare testi ve Continuity (Yates) düzeltmesi kullanılmıştır. Bulgular: Araştırma kapsamına alınan primipar kadınlarda sezaryen oranı \%60'tır. Araştırmaya katılan primipar kadınların yaş ortalaması $29.77 \pm 4.54$ ve \%38.4'ü 30-34 yaş aralığındadır. Çoğunluğu üniversite mezunu (\%69) ve çalışmaktadır (\%69). Ebe desteği algısının beklenenden fazla olma oranı; vajinal doğum yapanlarda \%73.3 ve sezaryen olanlarda 58.5'tir. Doğumda kaygı algısının beklenenden fazla olma oranı; sezaryen olanlarda \%39.3, vajinal doğum yapanlarda \%26.7'dir. Doğumda ağrı algısının beklenenden fazla olma oranı vajinal doğum yapanlarda \%83.9, sezaryen olanlarda \%22.2 'dir. Doğum sonu ağrı algısının beklenenden fazla olma oranı sezaryen olanlarda \%38.1, vajinal doğum yapanlarda \%19.4'tür. Korku algısı ve mahremiyet algısı açısından sezaryen olanlar ve vajinal doğum yapanlar arasında fark bulunmamıştır. Sonuç: Vajinal doğumda kadınların beklediklerinden daha çok ebe desteği algıladıkları sezaryen olan kadınların kaygı algılarının beklenenden daha yüksek olduğu, vajinal doğum esnasında beklenenden daha yüksek ağrı algılanırken sezaryen sonrası ağrının vaginal doğum sonrası ağrıya göre beklenenden daha yüksek algılandığı belirlenmiştir.

Anahtar kelimler: Vajinal doğum, sezaryen, doğum beklentisi, doğum algisı

\begin{abstract}
Aim: This study aimed to determine the effect of childbirth expectations of primiparous women who had vaginal delivery or cesarean section in a private hospital on their perceptions of childbirth experience. Material and Method:This retrospective and descriptive study was conducted in a private hospital of Medipol Healthcare Group. The study sample consisted of 450 primiparous women who applied to the hospital between February and July 2014 and agreed to participate in the study. Data were collected using a semi-structured “Question Form for Evaluating Expectation” and analyzed using the chi-square test, Fisher's exact test, and Yates’ continuity. Results: The mean age of the participants was $29.77 \pm 4.54$. Of them, $38.4 \%$ were between 30 and 34 years old and $60 \%$ had cesarean section. Most of the women were university graduates (69\%) and working (69\%). The rate of having a higher midwife support perception than expected was $73.3 \%$ for the women having vaginal delivery $58.5 \%$ for the women having cesarean section. The rate of having a higher anxiety perception than expected was $39.3 \%$ for those having cesarean section and $26.7 \%$ for those having vaginal delivery. The rate of having a higher childbirth pain perception than expected was $83.9 \%$ for those having vaginal delivery and $22.2 \%$ for those having cesarean section. Finally, the rate of having a higher postpartum pain perception than expected was $38.1 \%$ for those having cesarean section and $19.4 \%$ for those having vaginal delivery. No difference was found between the women having cesarean section and vaginal delivery in terms of fear perception and privacy perception. Conclusion:Midwife support was higher than expected during vaginal delivery. The level of anxiety perception was higher than expected during cesarean section, whereas the childbirth pain perception was higher than expected during vaginal delivery. The postpartum pain perception was higher in cesarean section than in vaginal delivery.
\end{abstract}

Key words: Vaginal delivery, cesarean section, childbirth expectation, perception on birth

\section{Giriş}

Doğum, kadın ve ailesi için önemli bir yaşam olayıdır. Kadınların doğum ile ilişkili gerçek olmayan beklentileri, onları bazen hayal

kırıklığına uğratabilmektedir. $\mathrm{Bu}$ durumda doğumun kadın için anlamı da olumsuz etkilenmekte, bunun sonucu olarak doğumu ve

\footnotetext{
Geliş Tarihi/Received:18-02-2016 / Kabul Tarihi/Accepted:19-11-2016

a Özel İstanbul Medipol Hastanesi, Ebe,sems as@hotmail.com

b Yrd.Doç.Dr.İstanbul Medipol Üniversitesi Sağlık Bilimleri Yüksekokulu, fokumus@medipol.edu.tr

Sorumlu yazar /correspondence:Şemsi Aslan, Özel İstanbul Medipol Hastanesi, Ebe,sems_as@hotmail.com
} 
bebek sahibi olmay1 olumsuz ve konforsuz bir süreç olarak algılayabilmektedir. $\mathrm{Bu}$, sadece doğum yapan kadının kendisini değil, çevresindeki diğer kadınları da etkileyebilmektedir. ${ }^{1}$

Beklenti, zihinsel bir tutumdur ve pozitif veya negatif inanç, tutum ve algıları içinde barındırır. $^{2}$ Kadınların doğum ile ilişkili beklentileri, doğum deneyimlerinden memnuniyet düzeylerini etkileyecek önemli bir kavramdır. Doğum ile ilişkili beklentiler kişisel, kültürel ve çevresel faktörlere bağlıdır. Kadınların negatif beklentileri onların kendilerini güçsüz hissetmelerine neden olmakta ve beden imaj1, öz yeterlilik ve maternal sağ $\breve{l g ̆} 1$ olumsuz etkilemektedir. ${ }^{3,4}$ Negatif ve travmatik bir doğum deneyimi sonraki doğumda korkuya neden olmaktadır. $^{5}$

Kadınların doğum ile ilişkili beklentileri ve bireysel doğum deneyimleri arasındaki tutarsızlık doğum şekli ile ilgili tutumlarını etkileyebilir ve isteğe bağlı sezaryene yönelmelerine neden olabilir. Türkiye, OECD ülkeleri arasında en yüksek sezaryen oranlarına sahip bir ülkedir. ${ }^{6}$ Sağlık Bakanlığı, Sağlık İstatistikleri 2014 verilerine göre, Türkiye'de sezaryen oran1 2002 y1linda \%21 iken 2014'te $\% 51$ 'e yükselmiştir. ${ }^{7}$ Şüphesiz bunun nedenleri çok çeşitlidir. Sezaryen oranlarının artışında kadınların vajinal doğum ile ilgili negatif beklentilerinin önemli bir etkisi vardır. Türkiye'de kadınlar, çoğunlukla doğum ve doğum sonu süreçlerden dolayı endișelenmekle beraber doğum esnasında sağlık çalışanlarının nazik olmayan yaklaşımlarından dolayı da doğum korkusu yaşamaktadırlar. ${ }^{8-10}$ Türkiye'de sezaryen oranlarındaki aşırı yükselmenin önüne geçmek için primer sezaryen oranını dikkate alan çalışmalar başlatılmıştır. Son verilere göre primer sezaryenin tüm doğumlar içindeki payı \%26.3' tür. ${ }^{7}$ Yani primer sezaryen oranlarımız da henüz DSÖ tarafindan önerilen \%10-15 aralığına ulaşamamıştır. ${ }^{11}$

Kadınlar doğum ile ilgili olumsuz beklentilerinden dolayı sezaryene ve özel hastanelere yönelmektedir. Türkiye'de özel hastanelerde sezaryenin tüm doğumlar içindeki pay1 69.5, primer sezaryenin payı ise 37.3'tür. ${ }^{7}$ Türkiye' de sağlık sektöründe özelleşmeye doğru olan eğilim doğumların da daha çok özel hastanelere taşınmasına neden olmuștur. Özel hastanelere başvuran kadınların doğum ile ilgili negatif beklentileri, özel hastane hekimlerinin daha çok gelir elde etme kaygıları ile örtüşmekte ve dolayısıyla sezaryen oranları da artmaktadir.
Özel hastanelerdeki bu artış, ülke genelindeki ortalamaları da etkilemektedir. Türkiye'de çoğunluğun özel hastanelere başvurduğu halde, bu hastanelere başvuran kadınların beklentileri ve algıları hakkında yeterince literatür verisine rastlanmamaktadır. Bu düşünceden yola çıkılarak bu araştırma, özel hastanede vajinal doğum yapan veya sezaryen olan primipar kadınların doğum deneyim algıları üzerine doğum beklentilerinin etkisini belirlemek amaciyla yapılmıştır.

\section{Gereç ve Yöntemler}

\section{Araştırmanın Tipi ve Örneklemi}

Araştırma retrospektif tanımlayıcıyı araştırma olarak yapılmıştır. Araştırma verileri, ŞubatTemmuz 2014 tarihleri arasında, Medipol Sağlık Grubu'na bağlı özel bir hastanede toplanmıştır. Araştırmanın yapıldığı hastaneye araştırmadan önceki altı ayda 2516 kadın doğum için başvurmuştur. Örneklem büyüklüğü hesaplamak için evreni bilinen formülünden yararlanılmıştır. ${ }^{12}$

$$
\begin{aligned}
& \mathrm{n}=\frac{\mathrm{Nt} \mathrm{t}^{2} \mathrm{pq}}{\mathrm{d}^{2}(\mathrm{~N}-1)+\mathrm{t}^{2} \mathrm{pq}} \quad \begin{array}{ll}
\mathrm{n}: \text { Örnekleme } \\
\text { alınacak } & \text { birey } \\
\text { sayıs1 } & \mathrm{t}: 1.96
\end{array} \\
& \text { p: } 0.66 \\
& \text { q: } 0.34 \\
& \text { d: } 0.05 \\
& \text { 2516. }(1.96)^{2} \text {. 0.373. 0.627 } \\
& \mathrm{n}= \\
& n=346 \\
& (0.05)^{2} \cdot(2516-1)+(1.96)^{2} \cdot 0.373 \cdot 0.627
\end{aligned}
$$

Hesaplama yapılırken Türkiye Halk Sağlığı 2012 verilerine göre \%37.3 olan özel hastanelerdeki primer sezaryen hızı dikkate alınmıştır. ${ }^{7} \mathrm{Bu}$ verilere göre örneklem büyüklüğü \%5 önemlilik düzeyinde 346 olacak şekilde hesaplanmıştır. Kayıplar olabileceği göz önüne alınarak 450 kadın araştırma kapsamına alınmıştır.

Örneklem seçim kriterleri

- Primipar olmas1

- 37-42 gebelik haftası aralığında doğumu gerçekleştirmiş olması

- Canlı doğum olmasi,

- Sorulacak soruları anlayıp kavrayacak düzeyde Türkçe bilmesi,

Araştırma dışı bırakılma kriterleri;

- Preterm eylem,

- Çoğul gebelikler,

- Multipar gebeler,

- Türkçe bilmeyen kadınlar 
- Sorulacak soruları anlayip kavrayabilme yeteneğine sahip olmayan,

- Çalışmaya gönüllü olarak katılmayı kabul etmeyen kadınlar

\section{Araştırmanın Sorusu}

Sezaryen olan ve vajinal doğum yapan kadınların arasında doğum beklentileri ve doğum ile ilişkili algıları yönünden fark var mıdır?

\section{Verilerin Toplanması}

Kadın Doğum Kliniği'ne başvuran ve örneklem seçim kriterlerine uyan lohusalara vajinal doğum sonrası birinci gün, sezaryen sonrası ikinci gün içinde araştırma hakkında bilgi verilerek yazılı ve sözlü onamları alınmıştır. Veri toplama formları araştırmaya katılmayı kabul edenlere yüz yüze görüşme yöntemi kullanılarak uygulanmıştır. Verilerin toplanmasına 6 Şubat 2014 tarihinde başlanmış, haftanın belirli günlerinde ve örneklem sayısına ulaşıncaya kadar veri toplamaya devam edilmiştir. Her bir görüşme 15-20 dakika sürmüştür. Araştırmanın veri toplama aşaması 31 Temmuz 2014 tarihinde sona ermiştir. Veri toplama aracı olarak "Tanımlayıcı Bilgi Formu" ve "Beklenti Değerlendirme Soru Formu" kullanılmıştır

Tablo 1. Primipar Kadınların Sosyodemografik Özelliklerinin Doğum Şekline Göre Karşılaştırılması

\begin{tabular}{|c|c|c|c|c|c|}
\hline \multirow{2}{*}{$\begin{array}{l}\text { Sosyodemografik } \\
\text { Özellikler }\end{array}$} & Vajinal & Sezaryen & Toplam & \multirow{2}{*}{$\chi^{2}$} & \multirow{2}{*}{$\mathrm{p}$} \\
\hline & n (\%) & n (\%) & $n(\%)$ & & \\
\hline$Y_{a s ̧}^{1}$ & $30.47 \pm 4.55$ & $28.72 \pm 4.33$ & $29.77 \pm 4.54$ & \multirow[t]{2}{*}{$\mathrm{t}:-4.078$} & \multirow[t]{2}{*}{$0.001^{* *}$} \\
\hline $19-24$ y1l & 28 ( 54.9$)$ & $23(45.1)$ & 51 ( 11.3 ) & & \\
\hline $25-29 \mathrm{yll}$ & $75(45.2)$ & $91(54.8)$ & 166 ( 36.9$)$ & \multirow{3}{*}{12.017} & \multirow{2}{*}{$0.007 * *$} \\
\hline $30-34$ y1l & $60(34.7)$ & 113 ( 65.3) & $173(38.4)$ & & \\
\hline 35 yıl ve üzeri & $17(28.3)$ & $43(71.7)$ & $60(13,3)$ & & \\
\hline \multicolumn{6}{|l|}{ Öğrenim düzeyi ${ }^{1}$} \\
\hline Ortaokul ve daha az & 16 ( 8.9 ) & $18(6.7)$ & $34(7.6)$ & \multirow{3}{*}{5.661} & \multirow{3}{*}{0.059} \\
\hline Lise & $51(28.3)$ & $54(20)$ & 105 ( 23.3$)$ & & \\
\hline Üniversite & $113(62.8)$ & $198(73.3)$ & $311(69.1)$ & & \\
\hline \multicolumn{6}{|l|}{ Çalışma durumu ${ }^{1}$} \\
\hline Çalışmıyor & $70(47.3)$ & 78 ( 52.7) & 148 ( 32.9$)$ & \multirow{3}{*}{4.591} & \multirow{2}{*}{$0.021^{*}$} \\
\hline Çalışıyor & $111(36.8)$ & 191 ( 63.2 ) & $33(69.1)$ & & \\
\hline \multicolumn{5}{|l|}{ Aile tipi $^{2}$} & \\
\hline Çekirdek aile & 170 ( 39.1 ) & 265 ( 60.9 ) & 435 ( 96.7) & \multirow{2}{*}{3.520} & \multirow{2}{*}{0.061} \\
\hline Geniş aile & $10(66.7)$ & $5(33.3)$ & 15 ( 3.3$)$ & & \\
\hline \multicolumn{6}{|l|}{ Ekonomik durum ${ }^{1}$} \\
\hline Gelir giderden fazla & 47 ( 39.2 ) & $73(60.8)$ & $120(26.7)$ & \multirow{4}{*}{5.032} & \multirow{3}{*}{0.081} \\
\hline Gelir gidere denk & 125 ( 39.2 ) & $194(60.8)$ & $319(70.9)$ & & \\
\hline Gelir giderden az & $8(72.7)$ & $3(27.3)$ & $11(2.4)$ & & \\
\hline \multicolumn{5}{|l|}{ Doğum yeri (bölge $)^{2}$} & \\
\hline Marmara & $90(37.8)$ & 148 ( 62.2$)$ & 238 ( 52.9 ) & \multirow{6}{*}{2.907} & \multirow{6}{*}{0.714} \\
\hline Karadeniz & $24(37.5)$ & $40(62.5)$ & $64(14.2)$ & & \\
\hline İç anadolu & $22(46.8)$ & $25(53.2)$ & $47(10.4)$ & & \\
\hline Ege ve akdeniz & $10(45.5)$ & $12(54.5)$ & $22(4.9)$ & & \\
\hline Doğu ve güneydoğu & $21(39.6)$ & $32(60.4)$ & $53(11.8)$ & & \\
\hline Yurt diş1 & $13(50.0)$ & $13(50.0)$ & $26(5.8)$ & & \\
\hline \multicolumn{6}{|l|}{ Sağllk güvencesi ${ }^{2}$} \\
\hline Özel sigorta & $19(39.6)$ & $29(60.4)$ & $48(10.7)$ & \multirow{5}{*}{6.354} & \multirow{5}{*}{0.174} \\
\hline Emekli sandiğ 1 & $8(50.0)$ & $8(50.0)$ & $16(3.6)$ & & \\
\hline Bağ-kur & $8(72.7)$ & $3(27.3)$ & $11(2.4)$ & & \\
\hline SSK & 132 ( 38.2 ) & $214(61.8)$ & 346 ( 76.9$)$ & & \\
\hline Yok & $13(44.8)$ & $16(55.2)$ & $29(6.0)$ & & \\
\hline
\end{tabular}




\section{Tanımlayıcı bilgi formu}

Tanımlayıcı Bilgi Formu, araştırmacılar tarafından literatür taranarak geliştirilmiştir. Bu form kadınların sosyodemografik özelliklerini belirlemek amacıyla uygulanmıştır.

\section{Beklenti değerlendirme soru formu}

Beklenti değerlendirme formu literatür taranarak ve klinik hastane uygulamaları dikkate alınarak araştırmacılar tarafından geliştirilmiştir. Kadınların vajinal doğum ya da sezaryen sırasında ebe desteği, korku, kaygı, ağrı, doğum sonras1 ağr1 ve mahremiyetin korunmas1 olmak üzere alt1 parametrede değerlendirilmiş̧ir. Her parametre için beklentilerin karşılanma düzeyi üç boyutta ele alınmıştır. Ön uygulamadan sonra gerekli düzenlemeler yapılarak araştırma için hazır hale getirilmiştir.

\section{Verilerin Değerlendirilmesi}

Çalışmada elde edilen bulgular değerlendirilirken, istatistiksel analizler için IBM SPSS Statistics 22 (IBM SPSS, Türkiye)

Tablo 2. Primipar Kadınların Doğum ile İlişkili Algılarının Doğum Şekline Göre Karşılaştırılması

\begin{tabular}{|c|c|c|c|c|c|}
\hline \multirow[b]{2}{*}{ Doğuma ilişkin algıları } & Vajinal & Sezaryen & Toplam & \multirow{2}{*}{$\chi^{2}$} & \multirow{2}{*}{$\mathrm{p}$} \\
\hline & n (\%) & n (\%) & $n(\%)$ & & \\
\hline \multicolumn{6}{|l|}{ Ebe desteği algıs1 } \\
\hline Beklenenin altında & $8(4.4)$ & $16(5.9)$ & $24(5.3)$ & \multirow{3}{*}{10.476} & \multirow{3}{*}{$0.005^{* *}$} \\
\hline Beklenen düzeyde & $40(22.2)$ & $96(35.6)$ & $136(30.2)$ & & \\
\hline Beklenenden fazla & $132(73.3)$ & $158(58.5)$ & $290(64.4)$ & & \\
\hline \multicolumn{6}{|l|}{ Korku algis1 } \\
\hline Beklenenin altında & $57(31.7)$ & $83(30.7)$ & $140(31.1)$ & \multirow{3}{*}{1.025} & \multirow{3}{*}{0.599} \\
\hline Beklenen düzeyde & $57(31.7)$ & $76(28.1)$ & $133(29.6)$ & & \\
\hline Beklenenden fazla & $66(36.7)$ & $111(41.1)$ & 177 (39.3) & & \\
\hline \multicolumn{6}{|l|}{ Kayg1 algis1 } \\
\hline Beklenenin altında & $62(34.4)$ & $81(30.0)$ & $143(31.8)$ & \multirow{3}{*}{7.785} & \multirow{3}{*}{$0.020 *$} \\
\hline Beklenen düzeyde & $70(38.9)$ & $83(30.7)$ & $153(34)$ & & \\
\hline Beklenenden fazla & $48(26.7)$ & $106(39.3)$ & $154(34.2)$ & & \\
\hline \multicolumn{6}{|l|}{ Ağr1 alg1S1 } \\
\hline Beklenenin altında & $5(2.8)$ & $161(59.6)$ & 166(36.9) & \multirow{3}{*}{183.761} & \multirow{3}{*}{$0.001 * *$} \\
\hline Beklenen düzeyde & $24(13.3)$ & $49(18.1)$ & $73(16.2)$ & & \\
\hline Beklenenden fazla & $151(83.9)$ & $60(22.2)$ & 211 (46.9) & & \\
\hline \multicolumn{6}{|l|}{ Doğum sonu ağr1 algıs1 } \\
\hline Beklenenin altında & $85(47.2)$ & 77 (28.5) & $162(36.0)$ & \multirow{3}{*}{22.815} & \multirow{3}{*}{$0.001 * *$} \\
\hline Beklenen düzeyde & $60(33.3)$ & $90(33.3)$ & $150(33.3)$ & & \\
\hline Beklenenden fazla & $35(19.4)$ & $103(38.1)$ & $138(30.7)$ & & \\
\hline \multicolumn{6}{|l|}{ Mahremiyet algis1 } \\
\hline Beklenenin altında & $9(5.0)$ & $11(4.1)$ & $20(4.5)$ & \multirow{3}{*}{1.715} & \multirow{3}{*}{0.424} \\
\hline Beklenen düzeyde & $33(18.3)$ & $63(23.3)$ & 96 (21.3) & & \\
\hline Beklenenden fazla & $138(76.7)$ & $196(72.6)$ & $334(74.2)$ & & \\
\hline Ki Kare Test, ${ }^{*} p<0.05^{*}$ & 0.01 & & & & \\
\hline
\end{tabular}

programı kullanılmıştır. Çalı̧̧ma verileri değerlendirilirken tanımlayıcı istatistiksel metodların (Ortalama, Standart sapma) yanı sıra Ki-Kare testi, Fisher's Exact Ki-Kare testi ve Continuity (Yates) düzeltmesi kullanılmıştır.

Bağımsız değişkenler: Kadınların yaşı, eğitim durumu, mesleği, aile tipi, sağlık güvencesi.

Bağımlı değişkenler: Doğum şekli.

\section{Araştırmanın Etik Yönü}

Araştırmanın etik kurul onayı; İstanbul Medipol Üniversitesi Girişimsel Olmayan Klinik Araştırmalar Etik Kurulu Başkanlığı'ndan alınmıştır.

\section{Bulgular}

Araştırma kapsamına alınan primipar kadınların \%40’1 (180) vajinal doğum yapmış, \%60’1 (270) sezaryen olmuştur. Araştırmaya katılan primipar 
kadınların sosyodemografik özellikleri incelendiğinde (Tablo 1); yaş ortalamas1 $29.77 \pm 4.54$ ve $\% 38.4$ 'ü 30-34 yaş aralığındadır. Vajinal doğum yapan primipar kadınların yaş ortalamas1, sezaryen olan kadınlardan istatistiksel olarak anlamlı düzeyde yüksek bulunmuştur $(p=0.001)$. Yaş gruplarına göre incelendiğinde vajinal doğum yapan ve sezaryen olan primipar kadınlar arasında istatistiksel olarak anlamlı farklılık olduğu belirlenmiştir $(p=0.007)$. Primipar kadınlar arasında ileri yaşlara doğru sezaryen oranları artmaktadır.

Primipar kadınların \%69.1'i gelir getiren bir işte çalıştığını belirtmiştir. Primipar kadınların bir işte çalışması ile doğum şekli arasında istatistiksel olarak anlamlı bir ilişki olduğu belirlenmiştir $(p=0.021)$. Yapılan ileri analizlerde bu anlamlılı̆̆ın çalışan kadınlar arasında sezaryenin daha yaygın olmasindan kaynaklandığı ortaya çıkmıştır.

Araştırmaya katılan kadınların doğum ile ilişki algıları doğum şekline göre incelendiğinde (Tablo 2); ebe desteği algıları ile doğum şekli arasında istatistiksel olarak anlamlı ilişki olduğu belirlenmiştir $(\mathrm{p}=0.005)$. Yapılan ileri analizlerde ebe desteğinin beklenen düzeyin üstünde olmasının vajinal doğum yapan kadınlarda (\%73.3) sezaryen olanlara (\%58.5) göre ve ebe desteğinin beklenen düzeyde olmasının sezaryen olanlarda (\%35.6) vajinal doğum yapanlara (\%22.2) göre yüksek olduğu bulunmuştur.

Primipar kadınlarda doğum ile ilişkili kaygı algıları ile doğum şekli arasında istatistiksel olarak anlamlı ilişki olduğu belirlenmiştir $(\mathrm{p}=0.020)$. Yapılan ileri analizlerde sezaryen olan kadınlarda kaygı düzeyinin beklenenin üstünde olma oranının (\%39.3), vajinal doğum yapan kadınlardan (\%26.7) yüksek olduğu bulunmuştur.

Primipar kadınlarda doğumda hissedilen ağrı algıları ile doğum şekli arasında istatistiksel olarak anlamlı ilişki olduğu belirlenmiştir $(p=0.001)$. Yapılan ileri analizlerde vajinal doğum yapan kadınlarda doğumda hissedilen ağrının beklenenin üstünde olma oranının (\%83.9), sezaryen olan kadılardan (\%22.2), sezaryen olan kadınlarda doğumda hissedilen ağrının beklenenin altında olma oranının (\%59.6), vajinal doğum yapan kadınlardan (\%2.8) yüksek olduğu bulunmuştur.

Primipar kadınlarda doğum sonrası ağr1 algıları ile doğum şekli arasında istatistiksel olarak anlamlı ilişki olduğu belirlenmiştir $(\mathrm{p}=0.001)$. Yapılan ileri analizlerde vajinal doğum yapan kadınlarda doğum sonrası his- sedilen ağrının beklenenin altında olma oranının (\%47.2), sezaryen olan kadınların sezaryen sonrası hissedilen ağrıdan (\%28.5), sezaryen olan kadınlarda ise sezaryen sonrası hissedilen ağrının beklenenin üstünde olma oranının (\%38.1), vajinal doğum yapan kadınların doğum sonrası hissedilen ağrıdan (\%19.4) yüksek olduğu bulunmuştur.

Kadınların korku, mahremiyet algıları ile doğum şekli arasında istatistiksel olarak anlamlı ilişki bulunmadığı belirlenmiştir ( $\mathrm{p}>0.05$ ).

\section{Tartışma}

Araştırma kapsamına alınan primipar kadınların \%60'ının doğum şekli sezaryendir. Sezaryen oranı Erzurum'da yapılan araştırmada \%34.3, Trabzon'da yapılan araştırmada \%36, Kahramanmaraş'ta \%40.2, İzmir'de yapılan araştırmada \%40.2, Düzce'de yapılan araştırmada \%47.2, Manisa'da yapılan araştır-mada $\% 52$, Ankara'da yapılan araştırmada \%56 olarak saptanmıştır. ${ }^{13-19}$ Türkiye Sağlık Bakanlığı Sağlık İstatistikleri Yıllığ 12014 'e göre ülkemizde 2014 yılı sezaryen oranı \%51 'dir. ${ }^{7}$ Yapılan araştırmalar Türkiye verileri ile benzer olsa da araştırma grubumuzda sezaryen oranı Türkiye ortalamasının üzerindedir. Bu durumun araştırma grubumuzun özel hastanede doğum yapan kadınlardan oluşmasından kaynaklandığ 1 söylenebilir.

Araştırmada primipar kadınlar arasında ileri yaşlara doğru sezaryen olmaya daha çok eğilimli oldukları belirlenmiştir (Tablo.1). Yapılan araştırmalarda sezaryen olan primiparlarda anne yaşının, vajinal doğum yapanlara göre anlamlı derecede yüksek olduğu bulunmuştur. ${ }^{20,21}$ Başka bir araştırmada 18-24 yaş aralığındaki kadınlar sezaryen karar verme oranının diğer gruplara göre anlamlı derecede düşüktür. ${ }^{22}$ Ankara'da primipar kadınlarda yapılan başka bir araştırmada 30 yaş üzeri kadınların daha fazla sezaryen olduğu görülmüştür. ${ }^{21}$ İleri yaştaki kadınlarda vajinal doğumun daha riskli olabileceği düşüncesiyle sezaryen doğuma yöneldikleri düşünülmektedir. Yaş ortalaması açısından karşılaştırıldığında vajinal doğum yapan kadınlar sezaryen olan kadınlardan daha ileri yaşlardadır. Araştırma grubumuzda sezaryen olan kadınların yaş ortalamas1 $28.72 \quad(\mathrm{SD}=4.54)$ 'dir $\quad$ (Tablo.1). Benzer araştırmalarda sezaryen olan kadınların yaş ortalaması Isparta'da 28.09, Erzurum'da 29.5, İstanbul'da 28.9 olarak bulunmuştur. ${ }^{23-25}$ Araştırma sonuçlarımız sezaryen olan kadınların 
yaş ortalaması açısından diğer araştırmalarla benzer sonuçlara sahiptir.

Çalışmamızda kadınların çoğunluğu (\%67.1) gelir getiren bir işte çalışmaktadır. Araştırma grubumuzda çalışan kadınlarda sezaryen olma oranı daha yüksektir (Tablo 1). Benzer bir araștırmada çalışan kadınlar arasında sezaryen oranının yüksek olduğu saptanmıştır. ${ }^{20}$ Başka bir araştırmada çalışmayan kadınlar daha çok vajinal doğum yapmayı tercih etmiştir. ${ }^{22}$ Çalışan kadınlar, düzenli çalışma hayatına sahip olduklarından dolayı doğumlarını da planlama ihtiyacı duymaktadır. Sezaryen için ise günü ve saatinin planlanması mümkün olduğundan çalışan kadınların daha çok sezaryen olmayı tercih ettikleri düşünülmektedir.

Kadınların doğum ile ilişkili beklentilerine yönelik algıları doğum sonu süreçlere ve bebeğe uyum konularına önemli etkilere sahiptir. Kadınların doğum deneyimlerinden memnun olmalarına yardımcı olmak için onların gerçek beklentilerini ortaya çıkarmaya ihtiyaç vardır. Kadınlar doğum esnasında kendilerine destek olacak birine ihtiyaç duymaktadır. Bryanton et al (2006)'e göre kaliteli bir doğum deneyiminin en önemli belirleyicisi hemşirelik girişimleridir. ${ }^{26}$ Waldenström (1999) tarafından 1111 kadında yapılan araştırmada ebe desteğinin memnuniyeti olumlu yönde etkilediği saptanmıştır. ${ }^{27}$ Çin'de yapılan bir araştırmada bebek bekleyen anne ve babalar, sağlık çalışanlarının onlar için güven verici bir konforlu bir çevre sağlamaları yönünde önemli beklentileri olduğu ortaya çıkmıştır. ${ }^{28}$

Araştırmaya katılan kadınların, doğum esnasında ebe desteği algıları incelendiğinde; yarıdan biraz fazlası (\%64.4) beklenenin üstünde olduğunu ifade etmiştir (Tablo 2). Primipar kadınlarda yapılan bir araştırmada kadınların doğum esnasında sağlık personeli desteğini büyük çoğunlukla yeterli gördüğü ifade edilmiştir. Verilen bakımı yetersiz gören kadınlar (\%52.4), en fazla sağlık personelinin sayısal yetersizliğini neden olarak görmektedir. Ancak hastaların önemli bir bölümü (\%38.1) sağlık personelinin hastaları önemsemediklerini düşünmektedir. ${ }^{29}$ İstanbul'da yapılan başka bir araştırmada sezaryen olan kadınların \%44'ü, vajinal doğum yapanların \%36'sı beklentilerinin hiç karşılanmadığını ifade etmişlerdir. Annelerin beklentisi genelde davranış ve iletişim yönündedir. ${ }^{30}$ Lohusalarda yapılan başka bir araştırmada annelerin \%70'inin ebe/ hemşirelerden beklentisi olduğu saptanmıştır. Annelerin \%88'i sunulan hemşirelik bakımını iyi olarak değerlendirmiş ve bunun doğum sonu konforlarını olumlu yönde etkilediği (\%94) belirtilmiştir. ${ }^{31}$ Isparta'da yapılan bir araştırmada hastalar \%86.6 oranında hemşirenin ilgisini yeterli bulmaktadır. ${ }^{32}$ Araştırmamızda sezaryen olanlarda ebe desteğinin beklenen düzeyde olması, vajinal doğum yapanlarda beklenen düzeyin üzerinde olması anlamlı olarak daha yüksektir. 15288 kadında yapılan randomize kontrollü bir çalışmada sürekli destek alan kadınlarda vajinal doğum oranının daha fazla olduğu belirlenmiştir. $^{33}$ Doğum esnasında kadınların ebelere yönelik destek algıları arttıkça vajinal doğum yapma oranları artmaktadır.

Araştırmaya katılan kadınların, çoğunluğu (\%39.3) doğum veya sezaryen esnasında beklediğinden daha fazla korku yaşadığını ifade etmiştir. Doğum şekli ile kadınların korku beklentileri arasında istatistiksel olarak anlamlı ilişski bulunmamaktadır (Tablo 2). Benzer araştırmalarda kadınların doğum şekli ile doğum korkusu arasında anlamlı ilişki olmadığını ortaya çıkarmıştır. ${ }^{34,35}$ Kadınlarda doğum korkusu, doğumun süresini, müdahaleli doğum oranlarını ve acil sezaryen ihtiyacını artırıcı bir etkiye sahiptir. Ancak yine de doğumdan korkan kadınlar da korkmayan kadınlar gibi büyük oranda başarılı bir şekilde doğumunu yapmaktadır. ${ }^{36}$

Araştırmaya katılan kadınların çoğunluğu (\%34.2) doğum veya sezaryen esnasında beklenenin üstünde kaygı yaşadığını belirtmiştir. Sezaryen olan kadınların kaygı düzeyi vajinal doğum yapan kadınlardan daha yüksektir (Tablo 2). Dönmez ve Yeniel (2014) tarafindan İzmir'de yapılan araştırmada gebelerin antepartum kaygı puan ortalamalarının postpartum kayg1 puan ortalamalarından yüksek olduğu bulunmuştur. Gebe kadınların doğum yöntemi ne olursa olsun antepartum kaygı puan ortalamalarının yüksek olduğu, bu durum kadınların vajinal doğum ya da sezaryen doğuma karşı değil, doğumun kendisine karşı bir kayg1 durumu yaşadıklarını göstermektedir. ${ }^{34}$ Araştırmamızda kadınların doğum esnasında kaygı düzeyleri ile doğum şekli arasında ilişki bulunurken benzer araştırmalarda ilişski bulunmamaktadır. $\mathrm{Bu}$ durum araştırma grubumuza alınan kadınlarda elektif, acil sezaryen ayrımı yapılmamasından ileri gelebilir. Kadınların doğum esnasında yaşadıkları yüksek oranda kayg1, doğumun sezaryen ile sonuçlanmasına neden olduğunu söyleyebiliriz.

Araştırmaya katılan vajinal doğum yapanlar doğum esnasında beklediklerinin üzerinde ağrı yaşadıklarını ifade etmişlerdir 
(Tablo. 2). Ağrı, kadınlar için vaginal doğum ile ilişkili negatif bir beklentidir. Yine de kadınlar ağrıyı, vaginal doğumun doğal bir parçası olarak görmekte ve ağrı yaşamayı beklemektedir. ${ }^{37}$ Uçum ve ark (2010) tarafından Manisa'da 266 kadında yapılan araştırmada vajinal doğum yapanlar, sezaryen olanlara göre doğum olayının tahmin ettiklerinden daha ağrılı olduğunu söylemiştir. ${ }^{35}$ Kadınlar, vajinal doğumu sezaryene göre daha ağrılı bulmakta ve vajinal doğumda beklediklerinin üzerinde ağrı deneyimi yaşamaktadırlar.

Araştırmaya katılan kadınların doğum sonrası algıladıkları ağrı düzeyi sezaryen olanlarda beklenenin üzerinde olma oranı vajinal doğum yapanlara göre daha yüksektir (Tablo 2). Pinar ve ark (2009) tarafindan Ankara'da yapilan araştırmada sezaryen olan kadınlarda sezaryen sonrası sorun yaşama oranı, vajinal doğum sonrası sorun yaşama oranına göre yüksek bulunmuştur. Özellikle primipar kadınlar, multiparlara göre daha fazla sorun yaşamaktadır. ${ }^{31}$ Kadınlar sezaryen olarak vajinal doğum ağrısından kurtulduklarını düşünseler de doğum sonrası dönemde daha çok sorun yaşayabilmektedir.

Araştırmaya katılan kadınlarda mahremiyetin korunmas1 konusunda beklentileri incelendiğinde; çoğunluğu (\%95.5) beklenen düzeyde ve üzerinde olduğunu ifade etmiş, doğum şekli ile mahremiyet beklenti düzeyleri arasında ilişki bulunmamıştır (Tablo 2). Gelişmekte olan ülkelerde maternal bakım hizmetleri esnasinda mahremiyetin korunmas1, kadınların bakımdan memnuniyetleri açısından anahtar role sahiptir. Doğum esnasında yapılan uygulamalar kadınlarda utanma duygusuna neden olabilir ve bu da onların memnuniyet seviyesinin azalmasına ve doğumu olumsuz konfor ortamı olarak algılamalarına neden olabilir. ${ }^{38}$ Araştırma grubumuzda kadınların mahremiyet algısı oldukça yüksek düzeydedir. Araştırmanın yapıldığı hastanede genel olarak mahremiyetin korunmasına yönelik politikalar izlendiği için oranların yüksek olduğu düşünülmektedir.

\section{Sonuç ve Öneriler}

Özel hastanede vajinal doğum yapan veya sezaryen olan primipar kadınların doğum deneyim algıları üzerine doğum beklentilerinin etkisini belirlemek amacıyla yapılan araştırmada aşağıdaki sonuçlar elde edilmiştir;

- Sezaryen olan kadınlar, vajinal doğum yapan kadınlardan daha ileri yaştadır.
- Çalışan kadınlar daha çok sezaryen olmaya eğilimlidir.

- Vajinal doğum yapan kadınlar, sezaryen olanlara göre beklediklerinden daha fazla ebe desteği algılamıştır. Doğum esnasında ebe desteği, vajinal doğumu artırıcı bir özelliğe sahiptir.

- Sezaryen olan kadınlar, vajinal doğum yapan kadınlara göre beklediklerinden daha yüksek kaygı algılamışlardır.

- Vajinal doğum yapan kadınlar doğum esnasında, sezaryen olan kadınlar ise doğum sonrasında beklediklerinden daha fazla ağrı deneyimi algılamışlardır.

Araştırma sonuçları doğrultusunda şu önerilerde bulunulabilir;

- Çalışan kadınlar ve doğum kaygıları olan kadınlar için doğuma yönelik eğitim programları planlanmalı ve bu programlarından faydalanmaları için destek olunmalidır.

- Ebeler, gebelik ve doğum esnasinda kadınlara daha çok destek olmalıdır.

- Ülkemizde ebe desteği olan doğumlarla ilgili daha fazla araştırmaya ihtiyaç vardir.

\section{Kaynaklar}

1. Oweis A, Abushaikha L. Jordanian pregnant women's expectations of their first childbirth experience. Int J Nurs Prac 2004; 10 (6):26471

2. Highsmith S. Primiparous' expectations of childbirth: The impact of consciousness. J Prenat Perinat Psychol Health. 2006; 21 (2): 141-78

3. Fenwick J, Gamble J, Mawson J. Women's experiences of caesarean section and vaginal birth after caesarean: A Birthrites initiative. Int J Nurs Prac 2003; 9 (1): 10-7

4. Callister LC. Making meaning: Women's birth narratives. J Obstet Gynecol Neonatal Nurs 2004; 33 (4): 508-18

5. Waldenström U, Hildingsson I, Ryding EL. Antenatal fear of childbirth and its association with subsequent caesarean section and experience of childbirth. BJOG 2006; 113 (6): 638-46

6. OECD (2016), Caesarean sections (indicator). doi: 10.1787/adc3c39f-en (Accessed on 06 February 2016)

7. Sağlık Bakanlığı Sağlık İstatistikleri Yıllığı 2014 
http://ekutuphane.sagem.gov.tr/kitaplar/sagli k_istatistikleri_yilligi_2014.pdf.

8. Serçekuş P, Okumuş H. Fear associated with childbirth among nulliporous women in Turkey. Midwifery 2009; 25(2): 155-162

9. Duman, Z, Köken GN, Şahin FK, Coşar E, Arıöz DT, Aral İ. Sağlık çalışanlarının normal doğum ve sezaryen ile ilgili düşünceleri. Perinatoloji Dergisi 2007; 15(1): 7- 11

10. Kitapçığlu G, Yanıkkerem E, Sevil Ü, Yüksel D. Gebelerde doğum ve postpartum döneme ilişkin endişeler ve validasyon çalışması. ADÜ Tıp Fakültesi Dergisi 2008; 9(1): 47-54

11. WHO. Appropriate technology for birth. Labcet 1985; 2: 436-7

12. Sümbüloğlu K, Sümbüloğlu V. Biyoistatistik. 14.bs, Hatipoğlu Basım ve Yayım San. Tic. Ltd. Sti., Ankara 2010.

13. Konakçı SK, Kılıç B. İzmir'de sezaryen ile doğum sıklığı ve buna etki eden faktörler. Türkiye Klinikleri Obstetrik Jinekoloji Dergisi 2004; 14(2):88-95

14. Mayda AS, Acehan T, Altın S, Arıcan M, Uzunoğlu MY. Bir üniversite hastanesinde yaptırılan doğumların incelenmesi. TSK Koruyucu Hekimlik Bülteni 2006; 5(6): 408415

15. Coşkun A, Köstü B, Ercan Ö, Kıran H, Güven MA, Kıran G. Kahramanmaraş il merkezinde 2004 ve 2006 yıllarındaki doğumların karşılaştırılması. Türkiye Jinekoloji ve Obstetrik Derneği Dergisi 2007; 4(3): 168-72

16. Pınar G, Doğan N, Alıger L, Kaya N, Çakmak F. Annelerin doğum sonu konforunu etkileyen faktörler. Dicle Tip Dergisi 2009; 36(3): 184-90

17. Uçum EY, Kitapçığlu G, Karadeniz G. Kadınların doğum yöntemlerine bakış açısı, deneyim ve memnuniyetleri. Fırat Sağlık Hizmetleri Dergisi 2010; 5(13): 107-23

18. Aran T, Osmanağaoğlu MA, Şahin M, Bozkaya H. Düşük doz oksitosin protokolü ile doğum indüksiyonunun sonuçları. Bozok Tıp Dergisi 2012; 2(2): 12-7

19. Çelik AS, Türkoğlu N, Pasinlioğlu T. Annelerin doğum sonu yaşam kalitesinin belirlenmesi. Anadolu Hemşirelik ve Sağlık Bilimleri Dergisi 2014; 17(3): 151-57

20. Yaşar Ö., Şahin, FK, Coşar E, Köken GN, Cevrioğlu AS. Primipar kadınların doğum tercihleri ve bunu etkileyen faktörler.
Türkiye Klinikleri Jinekoloji Obstetrik Dergisi 2007; 17: 414-20

21. Gözükara F, Eroğlu K. İlk doğumunu yapmış kadınların (primipar) doğum şekline yönelik tercihlerini etkileyen faktörler. Hacettepe Üniversitesi Sağlık Bilimleri Fakültesi Hemşirelik Dergisi 2008; 15(1): 32-46

22. Vatansever Z, Okumuş H. Gebelerin doğum şekline karar verme durumlarının incelenmesi. Dokuz Eylül Üniversitesi Hemşirelik Dergisi 2013; 6(2): 81-87

23. Özkaya O. Süleyman demirel üniversitesi kadın hastalıkları ve doğum kliniğindeki 5 yıllık doğum oranları ve sezaryen endikasyonları. Süleyman Demirel Üniversitesi Tıp Fakültesi Dergisi 2005; 12(4): 36-9

24. Yılmaz M, İsaoğlu Ü, Kadanalı S. Kliniğimizde 2002-2007 y1lları arasında sezaryen olan hastaların incelenmesi. Marmara Medical Journal 2009; 22(2): 10410

25. Uzunçakmak C, Güldaş A, Aydın S, Var A, Özçam H. S.B. İstanbul Eğitim Araştırma Hastanesi kadın hastalıkları ve doğum kliniğinde 2005-2012yılları arasında sezaryen ile doğum yapan hastaların değerlendirilmesi. Istanbul Med J 2013; 14: 112-16

26. Bryanton J, Gagnon AJ, Johns C, Hatem M. Predictors of women's perceptions of the childbirth experience. JOGNN; 37: 24-34, $2008 . \quad$ DOI: $10.1111 / J .1552-$ 6909.2007.00203.x

27. Waldenstrom U. Experience of labour and birth in 1111 women. Journal of Psychosomatic Research 1999; 47(5): 471482

28. Zhang X, Lu H. Childbirth expectations and correlates at the final stage of pregnancy in Chinese expectant parents. International Journal of Nursing Sciences 2014;1:151-156

29. Timur S, Şahin NH. Kadınların doğumda sosyal destek tercihleri ve deneyimleri. Hemşirelikte Araştırma ve Geliştirme Dergisi 2010; 12(1): 29-40

30. Karakaplan S, Doğum Şeklinin Annelerin Doğum Sonu Konforuna ve Yenidoğan Üzerine Etkileri. Marmara Üniversitesi Sağlık Bilimleri Enstitüsü, Yüksek Lisans Tezi, İstanbul, 2007.

31. Pınar G, Doğan N, Alıger L, Kaya N, Çakmak F. Annelerin doğum sonu konforunu etkileyen faktörler. Dicle Tıp Dergisi 2009; 36(3): 184-90 
32. Uzun E, Güney M, Oral B, Özsoy M, Mungan T. Kadın hastalıkları ve doğum servisi: verilen hizmetlerle ilgili hasta memnuniyeti ve etki eden faktörler. Türk Jinekoloji ve Obstetrik Derneği Dergisi 2006; 3(3): 167-71

33. Hodnett ED, Gates S, Hofmery GJ, Sakala C. Continuous support for women during childbirth. Cochrane Database of Sistematic Reviews 2013, Issue 7.Art. No:CD003766. DOI: 10.1002/14651858.CD0033766.pub5.

34. Dönmez S, Yeniel ÖA, Kavlak O. Vajinal doğum ve sezaryen doğum yapan gebelerin durumluk kayg1 düzeylerinin karşılaştırılması. Gümüşhane Üniversitesi Sağlık Bilimleri Dergisi 2014; 3(3): 908-20

35. Uçum EY, Kitapçıŏlu G, Karadeniz G. Kadınların doğum yöntemlerine bakış açısı, deneyim ve memnuniyetleri. Firat Sağlik Hizmetleri Dergisi 2010; 5(13): 107-23

36. Adams S, Eberhard-Grand M, Eskild A. Fear of childbirth and duration of labour: a study of 2206 women with intended vaginal delivery. BJOG 2012; 119: 1238-46

37. Callister LC, Khalaf I, Semenic S, Kartchner $\mathrm{R}$, Vehvilainen-Julkunen K. The pain of childbirth: perceptions of culturally diverse women. Pain Manag Nurs 2003; 4 (4): 14554

38. Srivastava A, Bilal I Avan, Preety Rajbangshi and Sanghita Bhattacharyya. Determinants of women's satisfaction with maternal health care: a review of literature from developing countries BMC Pregnancy and Childbirth 2015; 15:97 